\title{
EDUCAÇÃO PROFISSIONAL E EDUCAÇÃO EMPREENDEDORA: UMA REFLEXÃO CRÍTICA DOS ASPECTOS TEÓRICOS E METODOLÓGICOS
}

\author{
Alexandre Meira Vasconcelos ${ }^{1}$ \\ Álvaro Guillermo Rojas Lezana² \\ Luciane Camilotti ${ }^{3}$ \\ Mauricio Ballarine ${ }^{4}$ \\ Rolando Vargas Vallejos ${ }^{5}$
}

\section{RESUMO}

No Brasil, o recente avanço da economia, da industrialização e da consequente difusão de tecnologias, as mudanças no mundo do trabalho e no contexto das organizações colocam em pauta a necessidade de transformações na educação profissional. Nesse sentido, este artigo discute o papel da educação profissional na atualidade para promover uma reflexão sobre a função do docente e das metodologias de ensino, assim como uma proposta de educação profissional relacionada à educação empreendedora. Para cumprir esse percurso, a análise foi realizada com base em textos teóricos. Em primeiro lugar, foram sinalizadas questões referentes às teorias que fundamentam a educação profissional, particularmente em Gramsci e Giroux, sobre o contexto e a aplicação de metodologias de ensino e sobre uma proposta de educação empreendedora. Na sequência, propõe-se o debate acerca do papel da educação profissional a partir de uma vertente política e emancipadora, identificada em Adorno e em Saviani. Longe de esgotar todas essas questões, mas sim de apresentar subsídios para uma necessária reflexão, apresentam-se algumas possibilidades teóricas e metodológicas de atuação da educação profissional.

Palavras-chave: Educação profissional. Educação empreendedora. Metodologias de ensino. Prática pedagógica. Formação docente.

\footnotetext{
${ }^{1}$ Mestre, e-mail: meira1970@gmail.com

2 Doutor, e-mail: lezana@deps.ufsc.br

3 Doutora, e-mail: luciane.camilotti@sc.senai.br

${ }^{4}$ Mestre, e-mail: mballarine@dn.senai.br

${ }^{5}$ Doutor, e-mail: rolando@dn.senai.br
} 


\section{INTRODUÇÃO}

A proposta desse artigo é discutir o papel da educação profissional diante da realidade atual, participando desse contexto, com uma perspectiva voltada ao diálogo, sem obstaculizar uma pretendida natureza crítica, à luz das teorias que fundamentam a educação profissional, sob uma perspectiva mais crítica, muito menos interessada em sua historiografia e muito mais motivada em colocar em diálogo diferentes pontos de vista. A proposta é colocar ou recolocar o docente como intelectual, resgatando Gramsci (2006) e Giroux (1997), buscar os conceitos e os contextos inerentes às metodologias de ensino e apresentar algumas possibilidades de atuação da educação profissional, como, por exemplo, a educação empreendedora.

Sob uma ótica crítica, "trata-se de desarticular dos interesses dominantes aqueles elementos que estão articulados em torno deles, mas não são inerentes à ideologia dominante e rearticulá-los em torno dos interesses dominados" (SAVIANI, 2009, p. 26). O pano de fundo que emerge dessa citação é o da força que se quer dar ao processo formativo, ou, diretamente, à educação profissional, em uma realidade histórica de significativa ausência de iniciativas que levem o sujeito aprendiz a uma condição privilegiada no mundo do trabalho.

De forma mais específica, pretende-se:

a) Resgatar o papel do docente como intelectual, passando por questões referentes à sua formação e à sua atuação, tratando-o como um dos principais agentes de transformação dentro do mundo da educação, porquanto ser o articulador entre as concepções metodológicas e a vida em sala de aula, entre as possibilidades de promover a autonomia ou a heteronomia do aprendiz;

b) refletir, de forma geral, sobre o papel das práticas pedagógicas, no sentido de contribuir para o alcance pretendido dos objetivos estabelecidos para a educação profissional;

c) possibilitar uma aproximação, inicial, com uma proposta de educação profissional, qual seja, a de uma educação empreendedora, sem defini-la como definitiva, nem tampouco isentá-la de críticas, mas com um interesse em avançar na discussão sobre como deve ser a educação profissional, diante dos aspectos aqui retratados. Nesse sentido, colocar a educação empreendedora na mesa de debates, como uma interseção de fundamentações teóricas e como espaço de escape de uma aparente incerteza intrínseca à educação profissional: a formação para o trabalho, sem negligenciar a possibilidade de emancipação do sujeito; e 
d) provocar o exercício de uma inteligência que possa transcender às questões metodológicas, sem diminuir a importância dessas últimas, mas sem omitir ou negligenciar as possibilidades de limites dessas. Tal provocação dirige-se para a ideia de que a inteligência deve prevalecer às metodologias. Nesta linha, e já adiantando, propõe-se, por exemplo, que o docente deva ser capaz de tomar decisões, além de ser capaz de cumprir uma prática pedagógica concebida previamente.

Nesse artigo são tratados dois temas relevantes, primeiro remete à educação infantil, sobretudo na primeira infância; e, além disso, ao esclarecimento geral, que produz um clima intelectual, cultural e social que não permite tal repetição. A primeira questão não é, obviamente, abordada na educação profissional, e não é, por isso, o foco deste artigo. A segunda questão é exatamente o caminho escolhido para tratarmos de nossas indagações, e discutiremos a relação que há entre este esclarecimento e o papel da educação profissional.

\section{MÉTODOS}

O artigo se enquadra como de abordagem teórica e descritiva, pois não adota qualquer caráter prescritivo ou orientador de práticas educativas, mas visa buscar entender sob óticas variadas a seguinte pergunta: Qual é o papel da educação profissional diante das questões de nossa atualidade? Esta questão é relevante e contemporânea porque os sujeitos que antes optaram pela não consciência e pelo desconhecimento e desprezo da condição humana não podem, de forma alguma, encontrar acolhimento nos processos formativos de hoje, e destes a educação profissional não está a parte.

A íntima vinculação entre a questão educacional e formativa e a reflexão teórica social, política e filosófica constitui a manifestação direta do núcleo temático essencial ao conjunto da obra de Adorno e da Escola de Frankfurt: a relação entre teoria e prática. Vale enfatizar, vínculo que será buscado aqui, nessa proposta de reflexão. A inspiração em Adorno é justamente para fortalecer a discussão, e já delinear os seus objetivos, porquanto em Adorno, a teoria social é na realidade uma abordagem formativa, e a reflexão educacional constitui uma focalização político-social. Uma educação política. Assim como em Gramsci (2006), Giroux (1997) e em Saviani (2009), outros autores que serviram de inspiração a essa discussão, toda educação é educação política.

Faz-se imperativo dimensionar a comparação entre o trabalho do proletário fabril e o trabalho do docente na sua totalidade, em uma sala de aula e em uma perspectiva tecnicista. $O$ exagero aqui fica para considerar e não perder de vista o potencial destrutivo desse modelo. E também, vale marcar essa passagem para, posteriormente, voltar e fazer a análise do ponto de vista do espaço ocupado pelo docente nas metodologias de formação. O resgate do docente como intelectual permite ou auxilia na consciência desses fatores e no enfrentamento dessas questões. 


\section{FUNDAMENTAÇÃO TEÓRICA}

A opção teórica adotada aqui percorre, ou pretende percorrer, uma reflexão de natureza crítica, vista sob um ponto de vista político, reconhecendo a existência e o significado das relações de dominação, e com uma motivação diretamente vinculada à promoção da emancipação do sujeito.

\subsection{Educação Profissional}

Constata-se no mundo do trabalho uma variedade de mudanças que impactam nas esferas sociais, culturais, econômicas e políticas, ao mesmo tempo em que são também originadas por elas. As necessidades do mundo produtivo estão diretamente relacionadas às transformações sociais, políticas e econômicas e, por conseguinte, provocam instabilidades na área da educação, que passa a ter que responder com a agilidade e a qualidade maior para responder às demandas de desenvolvimento planejadas. Com o surgimento e difusão de novas tecnologias e novas formas de organização do trabalho, com vieses conjunturais ou estruturais, constata-se a importância da educação profissional, e uma correspondente necessidade da elevação dos níveis de qualificação profissional dos trabalhadores e de alterações na legislação educacional.

"As novas concepções demandadas pela moderna gestão empresarial, as necessidades criadas pela explosão tecnológica, o novo enfoque dado ao conhecimento que, hoje, é considerado um instrumento gerador de competitividades e produtividade organizacional, têm alterado de forma significativa o contexto do processo de trabalho, repercutindo diretamente no mundo da educação, especialmente na educação profissional que, nos últimos anos, tem sido objeto de discussão voltada para a sua análise e funcionamento". (SERVIÇO NACIONAL DE APRENDIZAGEM INDUSTRIAL, 2009, p.9)

Não são poucas as pesquisas, os escritos e as reflexões acerca da educação profissional no Brasil, desenvolvidos por meio de diferentes abordagens, voltados a expectativas, objetos e resultados também diversos. Como exemplo, Lezana et al. (2009) trazem a experiência da abordagem do empreendedorismo no ensino fundamental, temática antes prerrogativa de cursos de ensino superior, com o intuito não de formar empresários, mas de estimular e desenvolver o espírito crítico, e a aptidão para a solução de problema s e a tomada de decisão, todas inerentes e essenciais à vida adulta, que são essenciais para se enfrentar desafios na vida pessoal e profissional.

Pode-se ver, segundo Manfredi (2002), que muitos desses estudos baseiam-se em duas grandes abordagens teóricas, uma delas, de maneira geral, com o foco em um determinado sistema escolar e nas políticas públicas e, a outra, com um foco na relação educação e trabalho, sob uma ótica histórico-crítica, muitas vezes alicerçada na literatura marxista. 
A educação política de Adorno relaciona-se profundamente com os aspectos que este artigo quer tratar de forma articulada, quais sejam, o papel do docente, o potencial de uma educação empreendedora, voltada à realização de projetos e as questões de cunho metodológico. E essa relação é evidenciada por meio de uma categoria que é intrínseca aos três itens citados, a experiência. Vejamos:

Creio que isto se vincula intimamente ao próprio conceito de racionalidade ou de consciência. Em geral este conceito é apreendido de um modo excessivamente estreito, como capacidade formal de pensar. Mas esta constitui uma limitação da inteligência, um caso especial da inteligência, de que certamente há necessidade. Mas aquilo que caracteriza propriamente a consciência é o pensar em relação à realidade, ao conteúdo - a relação entre as formas e estruturas do pensamento do sujeito e aquilo que este não é. Este sentido mais profundo de consciência ou faculdade de pensar não é apenas o desenvolvimento lógico formal, mas ele corresponde literalmente à capacidade de fazer experiências. Eu diria que pensar é o mesmo que fazer experiências intelectuais. Nesta medida e nos termos que procuramos expor, "a educação para a experiência é idêntica à educação para a emancipação" (ADORNO, 1995, p. 151).

No que diz respeito à formação profissional, aos seus correspondentes currículos, metodologias de ensino, processos de avaliação e itinerários formativos, há tendências e iniciativas diversas, que evidenciam concepções de trabalho, de comunidade, de desenvolvimento e de educação baseados em fundamentos e conceitos políticofilosóficos que divergem entre si. Esses conceitos foram, ao longo dos anos, constituídos social e historicamente, e também a eles são forçadas atualizações e novos significados, diante dos tempos atuais.

Podemos ver que, entre essas diferentes concepções, existem aquelas que entendem a educação profissional de uma forma relacionada a uma postura mais assistencialista, ou compensatória. Já é bem difundida essa ideia de que a educação profissional é direcionada aos pobres. Existem aquelas baseadas em uma postura mais tecnicista, ou como é difundida, baseada em uma racionalidade técnico-instrumental, que voltam seus esforços para uma formação direcionada à satisfação das forças produtivas. São processos formativos que se expressam por meio de ações concebidas para proporcionar, aos trabalhadores, condições de acompanhar e trabalhar pelas mudanças e inovações nos processos produtivos, para as transformações no mundo do trabalho. Trata-se de uma abordagem inteiramente sujeita, e vale dizer, somente sujeita, aos preceitos dos vigentes modelos econômicos.

Existe ainda a vertente baseada em uma proposta com foco em uma educação tecnológica, com foco no vínculo entre a formação técnica, leia-se, formação profissional, para não apenas designar a formação que ocorre nos cursos técnicos de nível médio, com o conhecimento científico. Trata-se de uma vertente que vislumbra uma perspectiva de formação de profissionais como "sujeitos coletivos e históricos" (MANFREDI, 2002), com forte aproximação às teorias de natureza social e histórico-crítica, aproximação esta que o presente artigo também pretende seguir. E ainda, vale citar: "Nessa mesma linha, há concepções que entendem a formação para o trabalho como uma das dimensões educativas do processo de formação humana" (MANFREDI, 2002, p. 57). 


\subsection{Educação Empreendedora}

Certamente há uma diversidade de alternativas a serem estudadas, possibilidades de uma educação que tem como objetivo a inserção no mercado de trabalho sim, mas sem que isso seja a finalidade última, sem que isso seja a única ideia por trás de um planejamento educacional. A opção aqui é pela educação empreendedora, entendida como um processo dinâmico de conscientização, reflexão, associação e aplicação que envolve transformar a experiência e o conhecimento em resultados aprendidos e funcionais. Nota-se a estreita e importante relação entre educação, experiência e conhecimento (LOPES, 2010).

Severino e Pimenta (apud Manfredi, 2002), emolduram o docente como um profissional essencial no processo de transformação social. Assim, de forma alguma podem ficar de lado dessas discussões, ausentes das decisões pedagógicas, metodológicas e, mais especificamente, curriculares, porquanto serem os principais agentes no processo formativo. Sem a participação dos docentes nessas questões, são significativas as possibilidades de não lograrem êxito as iniciativas a serem implementadas, por mais interessantes que pareçam. Essa relevância, adotada aqui como uma das premissas, e desenvolvida como um dos objetivos específicos desse artigo, não implica em uma opção teórica centrada apenas no ensino, no docente. Vale dizer, que a opção teórica aqui é centrada em uma perspectiva crítica, mas que não deixe de lado todas as vertentes que são consideradas essenciais para que o processo formativo seja de fato capaz de provocar, de induzir mudanças significativas na sociedade, e capaz de permitir, de fato, a emancipação e a formação das pessoas que passam pelos bancos escolares.

O resgate do papel do docente no processo formativo não é novidade e já faz parte da pauta das discussões a respeito das melhorias que são desejadas na educação profissional. Pretende-se aqui uma contribuição para esse debate, com a nuance indicando o docente como um intelectual, a partir dos escritos de Gramsci (2006), fazendo a relação com os intelectuais orgânicos e a partir de Giroux (1997), com a proposta declarada, dos professores como intelectuais transformadores.

O conceito de empreendedorismo, um tanto diferente e mais profundo do que usualmente é representado pelo senso comum, compõe os alicerces de uma base que objetiva a formação para o trabalho, a formação para o exercício crítico da cidadania, a formação para a emancipação e para a prática política. Em contrapartida, a educação empreendedora também se coloca como alternativa às propostas tradicionais. Estas últimas tratam da desagregação de conteúdos, ou seja, da tendência de as escolas separarem as disciplinas de forma cartesiana, sem que uma área converse com a outra, proporcionando conteúdos repetidos, muitas vezes desencadeados, sem relação alguma entre si e, pior ainda, dificultando o alcance, por parte dos estudantes, de uma visão integrada dos conhecimentos.

O processo da educação empreendedora baseia-se no autodirecionamento da aprendizagem, no desenvolvimento do pensamento crítico, porém prático e funcional, 
no desenvolvimento da pessoa e do cidadão. Baseia-se na realização de projetos diretamente relacionados à realidade dos estudantes e da comunidade, com o estímulo do pensamento criativo e inovador, capaz de provocar o progresso econômico, por um lado, e o progresso do indivíduo, do outro. Assim, podemos definir o empreendedor como aquele que inova, aquele que propõe formas diferentes de fazer as coisas, aquele que reorganiza os recursos produzindo ganho.

Vejamos um dos aspectos mais relevantes dessa visão empreendedora:

Algumas organizações têm estimulado o desenvolvimento de empreendedores coorporativos, pois a inovação é a principal fonte de diferencial competitivo no mundo globalizado. A inovação, entretanto, é notadamente mais bem sucedida e implementada quando o autor da ideia é também o responsável por disseminá-la e conduzir o projeto adiante. Assim, "a criatividade, dissociada de ação empreendedora, não basta" (LOPES, 2010, p. 12).

Com essa abordagem, muitas das questões que se colocam hoje no cotidiano da educação, como, por exemplo, o planejamento dos currículos e o uso das tecnologias educacionais, temas extremamente relevantes para o sucesso de qualquer proposta, passam a ser menos impactantes, pois com uma metodologia apropriada ao desenvolvimento de tal capacidade empreendedora, não há espaço para concepções equivocadas sobre a aplicabilidade dos currículos e das tecnologias, pois estes são tratados como meios, como instrumentos, voltados aos objetivos primeiros. E quais seriam os objetivos da educação empreendedora?

Segundo Lopes (2010), esses objetivos se referem a algumas ações, refletindo mudanças tanto na sociedade como um todo, quanto no próprio indivíduo, como, por exemplo, conscientizar a respeito do empreendedorismo e da carreira empreendedora, influenciar e desenvolver atitudes, habilidades e comportamentos empreendedores, desenvolver qualidades pessoais relacionadas às competências necessárias para o mundo moderno: criatividade, assumir riscos e responsabilidades, incentivar e desenvolver empreendedores, estimular a criação de negócios e de novas iniciativas, e ainda apoiar o desenvolvimento destas, gerar empregos, desenvolver conhecimentos, técnicas e habilidades focados no mundo dos negócios e necessários para a criação de uma empresa e auxiliar empreendedores e empresas, por meio de conhecimento e ferramentas, a melhorar sua competitividade.

A metodologia de ensino, levada ao seu extremo, no quesito prescrição de processos pedagógicos, de forma oposta à proposta empreendedora, pode ser metaforizada, ou comparada, dependendo do grau de crítica que se quer ter, com o desenvolvimento do trabalho fabril. Vejamos em Saviani:

Com efeito, se no artesanato o trabalho era subjetivo, isto é, os instrumentos de trabalho eram dispostos em função do trabalhador e este dispunha deles segundo seus desígnios, na produção fabril essa relação é invertida. Aqui, é o trabalhador que deve se adaptar-se ao processo de trabalho, já que este foi 
objetivado e organizado na forma parcelada. Nessas condições, o trabalhador ocupa seu posto na linha de montagem e executa determinada parcela do trabalho necessário para produzir determinados objetos. O produto é, pois, uma decorrência da forma como é organizado o processo. O concurso das ações de diferentes sujeitos produz assim um resultado com o qual nenhum dos sujeitos se identifica e que, ao contrário, Ihes é estranho (SAVIANI, 2009, p. 11).

\section{DISCUSSÃO}

Com consciência das limitações, que restringem claramente a função e os objetivos de um processo formal de educação, tem-se que admitir que este último não é responsável, na esfera social, pela emancipação humana, pois as relações de dominação e a constituição da hegemonia se realizam em todas as esferas da sociedade. Não obstante, há um papel importante que não deve ficar imerso nesse amontoado de relações, o de protagonismo na elaboração de um projeto que seja capaz de superar a alienação exacerbada pelo e no modo de produção capitalista.

A educação empreendedora se configura como uma alternativa à pedagogia política do capital. Segundo Lopes (2010), proporcionalmente diminui a ênfase e a dependência das economias das grandes empresas e cada vez mais nota-se um segmento de novas iniciativas desenvolvidas pelos empreendedores que ajudam no processo de atualização e de introdução de inovações tecnológicas. E ainda, observa-se o fator de inserção de pessoas no mercado de trabalho, o aumento de exportações e a geração cada vez maior de desenvolvimento econômico. Como se o próprio processo produtivo característico do capitalismo tivesse aberto uma janela de oportunidade para que, com suas próprias ferramentas, houvesse uma possibilidade de crescimento do sujeito, principalmente com a valorização de seu conhecimento e de suas capacidades. Como se, por um momento, pudéssemos fazer uma relação com o passado, com os antigos mestres artífices e seus aprendizes, quando cada um tinha a exata compreensão de toda a sua dinâmica de trabalho, onde não havia espaço para a desagregação de tarefas e a consequente alienação.

Será considerada a noção de intelectual a partir do comentário de Giroux (1997) sobre o conceito inicialmente apresentado por Gramsci (2006):

Essencial para o projeto de emancipação que informa nossa noção de estudos culturais é a reformulação do papel do intelectual dentro e fora da universidade. Estamos de acordo com Gramsci de que é importante ver os intelectuais em termos políticos. O intelectual é mais do que uma pessoa das letras, ou um produtor e transmissor de idéias. Os intelectuais são também mediadores, legitimadores, e produtores de idéias e práticas sociais, eles cumprem uma função de natureza eminentemente política (GIROUX, 1997, p.186). 
Pode-se dizer, segundo Giroux (1997), que o que é essencial para concretizar-se a ideia do intelectual transformador é a necessidade de tornar o pedagógico mais político e, também, o político mais pedagógico. No caso, tornar o pedagógico mais político quer dizer que a escolarização deve ser inserida na esfera política. O conhecimento científico a ser adquirido deve caminhar junto com a conscientização sobre as diferentes formas de poder, até para que sejam incorporadas no processo de aprendizagem. Ao optar-se pelo trabalho com projetos, por exemplo, em uma visão empreendedora, o conteúdo político evidencia-se de forma inevitável, pois se torna parte de um processo, inclusive, de negociação. E, passando pela concepção do projeto, desenvolvimento e apresentação, certamente são encontrados conteúdos pedagógicos importantes, e contextualizados, e altamente portadores de autonomia e criatividade.

O processo de tornar o político mais pedagógico quer dizer que devem ser utilizadas formas de pedagogia que incorporem interesses políticos que tenham um caráter emancipador. A proposta é que sejam utilizadas diferentes formas pedagógicas que tratam os aprendizes como sujeitos críticos, problematizando o conhecimento e argumentando-se em direção a um mundo qualitativamente melhor. Fica claro que as concepções curriculares e metodológicas devem estar constantemente atentas a esses preceitos, elas devem permitir que seus processos sejam capazes de criar essa consciência crítica, por meio da realização do ensino e da aprendizagem. "Em parte, isto sugere que os intelectuais transformadores assumam seriamente a necessidade de dar aos estudantes voz ativa em suas experiências de aprendizagem" (GIROUX, 1997, p. 163).

Tal concepção de docência contrapõe-se a uma concepção mais positivista, que muitas vezes fundamenta a elaboração e o desenvolvimento de metodologias de ensino, com a preconização de um passo a passo que praticamente inutiliza qualquer capacidade crítica do docente, qualquer iniciativa autônoma e decisória. O discurso positivista, ou tecnicista, tem como preocupações mais importantes o domínio de técnicas pedagógicas e a transmissão do conhecimento instrumental, em moldes muito bem formatados.

A docência pode, assim, a partir desse resgate da intelectualidade, não só contribuir para a conscientização política, mas também para fortalecer uma inteligência educacional capaz de consolidar-se como pré-requisito da implantação de uma determinada metodologia de ensino, e não o contrário. A criação e o desenvolvimento de metodologias de ensino, em si, não promove a gênese de capacidades críticas nos seus seguidores, capacidades estas, inclusive, necessárias para as próprias atualizações metodológicas. A inteligência, em si, pode ser capaz de realizar a reflexão crítica, de criar as metodologias, de revê-las, de aplicá-las com sabedoria e de reconhecer os seus desafios e limites, porque também os tem. E, definitivamente, os docentes, fazem parte dessa inteligência educacional, e não podem participar dos debates apenas como objetos de reformas educacionais, que por muitas vezes acabam reduzindo-os à condição de técnicos de alto nível, com a tarefa de cumprir as regras e os objetivos decididos por especialistas um tanto afastados da realidade cotidiana da sala de aula. (GIROUX, 1997). 
E, citando o autor:

\begin{abstract}
Para que os professores e outros se engajam em tal debate, é necessário que uma perspectiva teórica seja desenvolvida, redefinindo a natureza da crise educacional e ao mesmo tempo fornecendo as bases para uma visão alternativa para o treinamento e trabalho dos professores. EM resumo, o reconhecimento de que a atual crise na educação tem muito a ver com a tendência crescente de enfraquecimento dos professores em todos os níveis de educação é uma precondição teórica necessária para que eles efetivamente se organizem e estabeleçam uma voz coletiva no debate atual (GIROUX, 1997, p. 158).
\end{abstract}

O docente, ao apropriar-se criticamente dos currículos que satisfazem os objetivos pedagógicos específicos, estará combinando a reflexão e a prática acadêmica, colocandose na história com um intelectual transformador, de forma a dar condição para a realização dos itens referentes à uma educação empreendedora, de forma a defender e rever as metodologias de ensino, de forma a estar a serviço da educação dos alunos, para que estes se formem cidadãos reflexivos e ativos. Cabe, obviamente, à toda estrutura educacional, prover esses docentes das condições para que se tornem intelectuais.

Um dos aspectos tratados, é que a despeito da dificuldade de levar esse tema para a educação profissional, é justamente aí que reside a condição para que se leve a cabo tal projeto, pois esta formação precisa vincular-se diretamente ao trabalho, que deve se realizar coletivamente unindo o desenvolvimento de capacidades intelectuais às capacidades manuais, com conhecimento científico associado ao desenvolvimento de habilidades cognitivas capazes de uma leitura crítica da realidade e de conscientização. Ou seja, o espaço privilegiado da educação profissional é exatamente essa articulação simultânea entre o pensar e o realizar, com a construção do conhecimento produzido na escola tendo, obrigatoriamente, que ter sentido para o desempenhar das atividades da vida prática nos diversos campos de atuação, ou seja, "de um ensino quase puramente receptivo, dogmático, passa-se à escola criativa, passa-se à escola em que a autodisciplina intelectual e a autonomia moral são teoricamente ilimitadas" (GRAMSCI, 2006, p.20).

A educação seria impotente e ideológica se ignorasse o objetivo de adaptação e não preparasse os homens para se orientarem no mundo. Porém "ela seria igualmente questionável se ficasse nisto, produzindo nada além de pessoas bem ajustadas" (ADORNO, 1995, p. 143). 


\section{CONSIDERAÇÕES FINAIS}

A escola precisa preparar a sociedade para uma crítica elaborada com autonomia, que permita ao sujeito constituir-se livremente e cabe à educação profissional uma fatia dessa responsabilidade. Sua atribuição, como demonstrado, deve transcender a já complexa tarefa de formar os sujeitos para o mundo do trabalho. Retomando Gramsci (2006) e seu projeto filosófico e educacional, o que está em pauta é a possibilidade de emancipação, assegurada pela autonomia, com um potencial cada vez maior de realização da condição humana.

Não cabe relatar todas as alternativas e possibilidades de atuação da educação profissional. Privilegiou-se um determinado campo teórico, e foram feitas algumas opções para tratarmos esse tema tão complexo. Para ir mais além de um modelo de educação com características ditas progressistas, podemos, paralelamente, realizar um esforço significativo também em colocar a educação profissional em uma perspectiva mais crítica, com tonalidades mais políticas. Aqui, optamos por dois alicerces básicos, fundamentais: o docente atuando com um intelectual transformador e um modelo de educação profissional, baseado na educação empreendedora, que, se bem conduzidos, crê-se capazes de uma autonomia com relação às prescrições curriculares e metodológicas. Com a crença de que um sujeito autêntico e crítico, realizado pelo trabalho, possui condições de decidir por novos rumos para a coletividade, cremos também que a educação profissional pode, certamente, atuar para a realização do sujeito.

Para terminar essa conclusão, voltaremos a Adorno (1995), com o qual iniciamos nossa discussão, com o objetivo de nada finalizar, e sim de enfatizar a necessidade do avanço teórico e metodológico, ambos em paralelo, nas questões referentes à educação profissional.

Ao longo de todo o texto pretendeu-se apresentar um contexto onde, por se tratar de um tema peculiar às ciências humanas e sociais, não há respostas prontas, e, por conseguinte, não há fórmulas para tratar o assunto passando incólume de debates e críticas. Justamente o que não se quer é o apaziguamento da razão diante de tais desafios. A tensão deve ser mantida, a consciência deve permanecer atenta, e devem ser buscadas opções cada vez mais apropriadas ao desenvolvimento que se quer atingir no âmbito da educação profissional. 


\title{
ENTREPRENEURIAL EDUCATION AND PROFESSIONAL EDUCATION: A CRITICAL REFLECTION ON THEORETICAL AND METHODOLOGICAL ISSUES
}

\begin{abstract}
In Brazil, the recent advancement of economy, of industrialization and of the consequent diffusion of technology, of the changes in the workplace and in the context of organizations put forth the need for changes in professional education. Accordingly, this article discusses the present role of vocational education to promote reflection on the role of teaching and learning methodologies, as well as a proposal for professional education related to entrepreneurial education. To fulfill this course of action, the analysis was based on theoretical texts. Firstly, were flagged issues concerning theories underlying professional education, particularly in Gramsci and Giroux, about the context and application of teaching methodologies and on a proposal for entrepreneurial education. Furthermore, it is proposed the debate about the role of vocational education from a political and emancipatory position, identified in Adorno and Saviani. Far from exhausting all these questions, but rather to provide subsidies to a necessary discussion, we present some theoretical and methodological possibilities of performance of professional education.
\end{abstract}

Keywords: professional education. entrepreneurial education. teaching methodologies. pedagogical practice. teacher training.

\section{REFERÊNCIAS}

ADORNO, T. W. Educação e emancipação. Rio de janeiro: Paz e Terra, 1995.

GIROUX, H. A. Os professores como intelectuais: rumo a uma pedagogia crítica da aprendizagem. Porto Alegre: Artmed, 1997.

GRAMSCI, A. Cadernos do Cárcere: volume 2: os intelectuais, o princípio educativo, jornalismo. 4. ed. Rio de Janeiro: Civilização Brasileira, 2006.

LEZANA, Á. G. R. et al. Empreendedorismo no ensino fundamental: a experiência de uma escola privada brasileira. RGE - Revista de Gestão e Empreendedorismo, [S.I.], v. 1, n. 1, p. 5-20, 2009. 
LOPES, R. M. Educação Empreendedora. Rio de Janeiro, RJ: Elsevier, 2010.

MANFREDI, S. M. Educação profissional no Brasil. São Paulo: Cortez, 2002.

SAVIANI, D. Educação e democracia. 41. ed. rev. São Paulo: Autores Associados, 2009.

SERVIÇO NACIONAL DE APRENDIZAGEM INDUSTRIAL. Departamento Nacional. Norteador da prática pedagógica. 3. ed. Brasília, DF, 2009c. 107 p. (SENAI Formação Profissional por Competências; v3). ISBN 9788575193068.

\section{SOBRE OS AUTORES}

Engenheiro de Produção graduado pela Universidade Federal do Rio de Janeiro
(UFRJ); especialista em Administração de Pessoas pela Universidade Federal
do Paraná (UFPR); mestre em Engenharia de Produção pela Universidade
Federal de Santa Catarina (UFSC). Doutorando em Engenharia de Produção
pela mesma universidade. Atuou como consultor sênior na implantação de
sistemas de gestão em empresas privadas, públicas e do terceiro setor. Foi
docente e coordenador na Sociedade Educacional de Santa Catarina (Sociesc)
nos cursos de graduação de Tecnologia em Gestão da Qualidade e Tecnologia
em Fabricação Mecânica.

\begin{tabular}{|l} 
Graduação em Ingeniero Civil Químico - Universidad Catolica de Valparaiso \\
Chile (1979), mestrado em Engenharia de Produção pela Universidade \\
Federal de Santa Catarina (1982) e doutorado em Ingeniería Industrial - \\
Universidad Politécnica de Madrid (1995). Atualmente é professor Associado \\
3 da Universidade Federal de Santa Catarina. Tem experiência na área \\
de Engenharia de Produção, com ênfase em Emprendedorismo, atuando \\
principalmente nos seguintes temas: empreendedorismo, educação a \\
distância via internet, empreededores, educação continuada e mestrado a \\
distância.
\end{tabular}




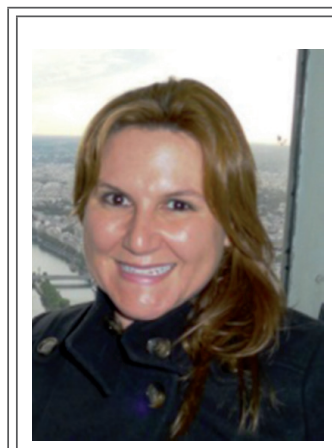

Luciane Camilotti
Graduação em Administração Habilitação em Comércio Exterior (1994), mestrado em Engenharia de Produção pela Universidade Federal de Santa Catarina (2001) e doutorado em Engenharia de Produção pela Universidade Federal de Santa Catarina (2007). Professora de cursos de Pós-Graduação e MBA nas disciplinas de Gestão Estratégica de Pessoas, Desenvolvimento Pessoal, Liderança Organizacional e Comportamento Empreendedor. Atua nas áreas de empreendedorismo, liderança, gestão de pessoas e gestão de destinos turísticos. Consultora do SENAI/SC. Aluna de pós-doutorado da Universidade Federal de Santa Catarina na área de Inteligência Organizacional

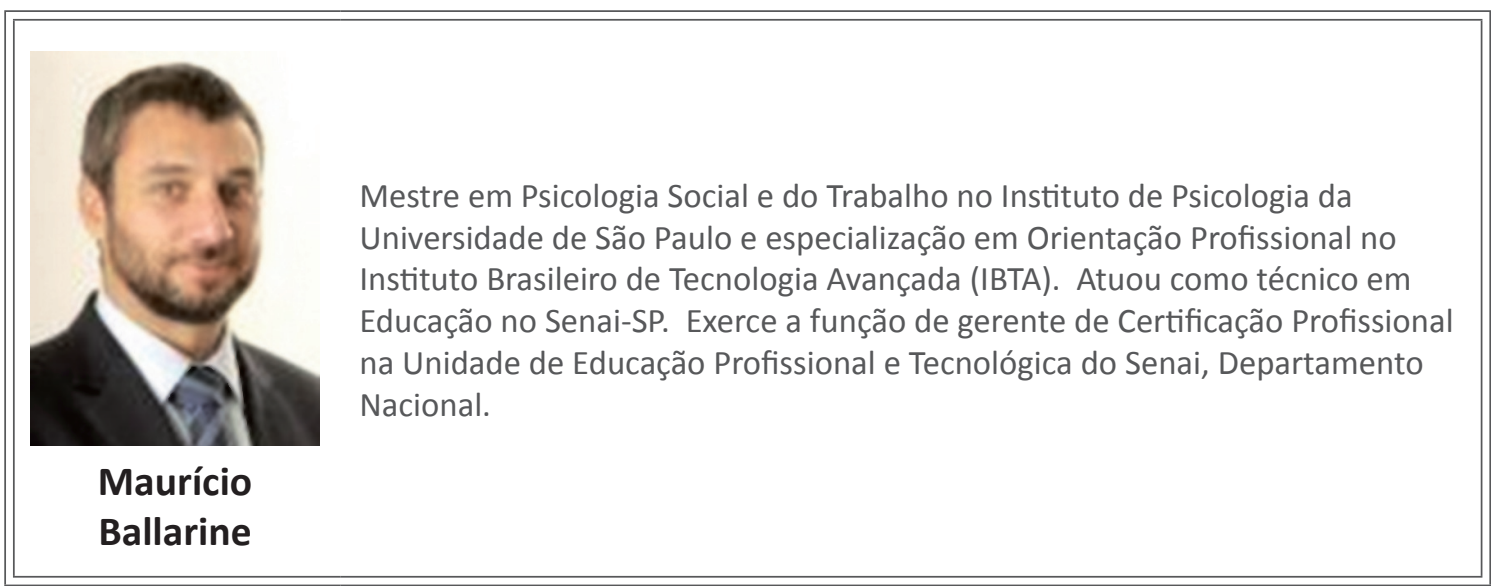

\begin{tabular}{|l|l|} 
Graduação em Engenharia Mecânica pela Universidade Técnica de Oruro \\
(1987), mestrado em Engenharia Mecânica pela Universidade Federal de Santa \\
Catarina (1992) e doutorado em Engenharia de Produção pela Universidade \\
Federal de Santa Catarina (2005). Atualmente é gerente executivo de educação \\
profissional e tecnológica do Serviço Nacional de Aprendizagem Industrial do \\
Departamento Nacional e professor da Universidade de Caxias do Sul. Tem \\
experiência na área de Fabricação (Engenharia Mecânica) e nas áreas de Redes \\
Colaborativas, Gestão do Conhecimento e Gestão da Inovação (Engenharia de \\
Produção). É membro ativo do COVE (Cooperation Infrastructure for Virtual \\
Enterprises and electronic Business) e revisor dos Journals of Manufacturing \\
Systems e Biomedical Science and Engineering. Avaliador do INEP/MEC.
\end{tabular}

